\title{
Associations Between Resilience, Community Belonging, and Social Participation Among Community-Dwelling Older Adults: Results From the Eastern Townships Population Health Survey
}

\author{
Mélanie Levasseur, ОT(C), PhD, ${ }^{a, b, c}$ Mathieu Roy, PhD, ${ }^{c, d, e}$ Bernard Michallet, PhD, ${ }^{c, f}$ \\ France St-Hilaire, PhD, ${ }^{g}$ Danielle Maltais, $\mathrm{PhD},{ }^{\mathrm{h}}$ Mélissa Généreux, $\mathrm{MD}^{\mathrm{b}, \mathrm{e}, \mathrm{i}}$
}

From the ${ }^{a}$ School of Rehabilitation, Faculty of Medicine and Health Sciences, Université de Sherbrooke, Sherbrooke, Québec; ${ }^{b}$ Research Centre on Aging, Health and Social Services Centre-Eastern Townships Integrated University Centre for Health \& Social Services-Sherbrooke Hospital University Centre (CIUSSS de l'Estrie-CHUS), Sherbrooke, Québec; 'Interdisciplinary Research Group on Resilience, Centre for Interdisciplinary Research in Rehabilitation of Greater Montreal, Montréal, Québec; ${ }^{d}$ Department of Family and Emergency Medicine, Faculty of Medicine and Health Sciences, Université de Sherbrooke, Sherbrooke, Québec; ${ }^{\circ}$ CIUSSS de l'Estrie-CHUS, Sherbrooke, Québec; ${ }^{f}$ Department of Speech Language Therapy, Université du Québec à Trois-Rivières, Trois-Rivières, Québec; ${ }^{g}$ Department of Management and Human Resources, Université de Sherbrooke, Sherbrooke, Québec; ${ }^{h}$ Department of Human and Social Sciences, Université du Québec à Chicoutimi, Saguenay, Québec; and ${ }^{i}$ Department of Community Health Sciences, Faculty of Medicine and Health Sciences, Université de Sherbrooke, Sherbrooke, Québec, Canada.

\begin{abstract}
Objective: To examine the associations between resilience, community belonging, and social participation, and the moderating effect of resilience on the association between community belonging and social participation among community-dwelling older adults.

Design: Cross-sectional; secondary analyses of the Eastern Townships Population Health Survey.

Setting: Community.

Participants: A sample $(\mathrm{N}=4541)$ of women $(n=2485)$ and men $(n=2056)$ aged $\geq 60$ years was randomly selected according to area. Most participants had $<14$ years of schooling, owned their dwelling, were retired, had 1 or 2 chronic conditions, and did not have depressive symptoms. Interventions: Not applicable.

Main Outcome Measures: Self-reported data on age, education, depressive symptoms, social participation, community belonging, and resilience were collected by phone interviewer-administered questionnaire. A social participation scale measured frequency of participation in 8 community activities. A 4-point Likert scale ranging from "very strong" to "very weak" estimated sense of belonging to the local community. Social participation and sense of belonging questions came from Statistics Canada surveys. Resilience was assessed with the 10-item Connor-Davidson Resilience Scale, capturing the ability to cope with adversity. Results: Controlling for age, education, and psychological distress, greater resilience and community belonging were associated with greater social participation among women $\left(R^{2}=.13 ; P<.001\right)$ and men $\left(R^{2}=.09 ; P<.001\right)$. The association between community belonging and social participation varied as a function of resilience, especially in men. Greater community belonging further enhanced social participation, especially among women $(P=.03)$ and men $(P<.01)$ with greater resilience (moderator effect).

Conclusions: Resilience moderates the association between community belonging and social participation among community-dwelling older women and, especially, men. Interventions targeting social participation should consider the potential impact of resilience on improving community belonging. Future studies should investigate why resilience moderates associations between community belonging and social participation, and how to enhance resilience among older adults.
\end{abstract}

Archives of Physical Medicine and Rehabilitation 2017;98:2422-32

Crown Copyright @ 2017 Published by Elsevier Inc. on behalf of the American Congress of Rehabilitation Medicine

Supported by the Public Health Department of the CIUSSS de l’Estrie-CHUS. At the time of the study, Mélanie Levasseur was a Junior 1 Fonds de la recherche en santé du Québec Researcher (\#26815); she is now a Canadian Institutes of Health Research New Investigator (\#360880).

Disclosures: none. 
A key determinant of active and healthy aging, ${ }^{1}$ social participation is defined as the person's involvement in social activities that provide interactions with others within the community. ${ }^{2}$ According to a meta-analytic review, ${ }^{3}$ people with adequate or strong social relationships had a $50 \%$ increased likelihood of survival compared with those with weaker or insufficient relationships. This influence is comparable to quitting smoking and superior to obesity and physical inactivity. Social participation is modifiable and results from the interaction between a person's characteristics and living environment. ${ }^{4}$ Sex is important, as women have been found to have greater social connectivity ${ }^{5}$ and are more likely to participate in community activities than men, except for sports and physical activities. ${ }^{6}$ Social participation in older adults helps them develop a better perception of their health, ${ }^{7}$ diminishes the consequences of aging, delays the onset of disabilities, ${ }^{8}$ and increases quality of life. ${ }^{9,10}$ Associated with needs for fundamental human relationships, belonging, and self-accomplishment, ${ }^{11}$ social participation is an essential target of health and social interventions.

Despite increasing interest in social participation, few studies $^{12-14}$ have examined its associations with other positive health measures such as resilience (ie, a force that drives a person to grow through adversity and disruptions). ${ }^{15}$ Resilience involves a situation of rupture, such as an imbalance after the onset of disabilities, and represents a growth opportunity, tapping into personal characteristics and support networks. When people are out of their comfort zone and look inside themselves, this rupture allows them to identify and then access and develop their resilient qualities. ${ }^{15}$ Such a positive adaptation allows the person to maintain or recover good mental health after adversity or stressful experiences, ${ }^{16}$ and to focus on competences, resources, strengths, capacities, and protective factors. ${ }^{14,17}$ Resilience has been found to moderate associations between traumatic events and mental health outcomes (eg, depressive symptoms in individuals exposed to childhood abuse or other traumas). ${ }^{18}$ By definition, a moderating effect changes (ie, weakens, amplifies, or even reverses) a relationship. ${ }^{19}$ With or without such events, resilient people might persist in their social participation efforts while others will give up. Additionally, people with greater resilience might look for growth opportunities by participating more in their community. Several studies demonstrated that having a positive relationship with another person and good social support are among the key factors for resilience. ${ }^{12}$ Older Australians with greater social engagement reported less psychological distress than those with lower social engagement. ${ }^{13}$ Being more physically and socially active and more persistent in pursuing goals, as well as having a wider range of interests and hobbies and a greater sense of purpose in life, were among the resources identified by older adults as most important for helping people cope with challenges and changes. Because it makes people feel useful and gives them a better understanding of their value,$^{20}$ helping others has also been found to enhance resilience. ${ }^{21-23}$ Finally, personal beliefs influence people's resilience ${ }^{24}$ and are determined by their experience and culture, as well as the beliefs of their family and friends. ${ }^{25}$

Influenced by social support and the environment, community belonging is also a key consideration in studies on social participation and resilience. Community belonging can be defined by a person's positive perception of the neighborhood as promoting

\section{List of abbreviations: \\ HDM-DCP Human Development Model-Disability Creation Process}

social support and cohesion, social ties, and mutual respect among residents. $^{26}$ Environmental buoying (ie, facilitators such as engagement opportunities and social support) can support personal competencies, which can in turn enable greater social participation. ${ }^{27,28}$ Personal perceptions of the area as neighborly are independently associated with a greater likelihood of social activities ${ }^{29}$ and well-being. ${ }^{30}$ In addition to being associated with better physical and mental health, ${ }^{31}$ a positive perception of the neighborhood is associated with higher self-esteem, a better developed social network, and greater social participation. ${ }^{32}$ Perceiving the neighborhood as being more socially cohesive moderates the association between poorer physical functioning and higher distress in community-dwelling older South Australians. ${ }^{13}$ A United Kingdom cross-sectional survey ${ }^{29}$ showed that viewing one's community as friendly and pleasant was associated with a greater probability of doing more social activities, regardless of older adults' demographic and socioeconomic characteristics. Another cross-sectional study ${ }^{33}$ of older Montrealers (Quebec, Canada) found that seniors with a strong sense of belonging to their neighborhood, compared with those with a weaker sense, participated more frequently in community activities $(P<.01)$. Finally, a photovoice study ${ }^{34}$ of well older adults in an urban context demonstrated that social participation is promoted through community belonging, acceptance of differences and change, volunteerism, interaction with others, and recognition. To our knowledge, associations between resilience, community belonging, and social participation have not been investigated.

Considering conceptual frameworks such as the Human Development Model-Disability Creation Process (HDM-DCP; fig $1),{ }^{4}$ the International Classification of Functioning, Disability and Health, ${ }^{35}$ and the literature discussed above, higher resilience and stronger community belonging could jointly and additively explain greater social participation (fig 2). The HDM-DCP, which has several similarities with the International Classification of Functioning, Disability and Health, ${ }^{36}$ specifically illustrates interactions between intrinsic personal factors (eg, age, sex, sociocultural identity, organic systems, and abilities, defined as the intrinsic capability of an individual to accomplish a physical or mental activity regardless of the environment, and including community belonging and resilience), extrinsic environmental factors (physical and social environments that determine the context and organization of a society), and social participation (see fig 1). ${ }^{4}$ While community belonging is categorized under affectivity in the HDM-DCP, where affectivity is a behavioral ability among personal factors, resilience might, in agreement with Davydov et al, ${ }^{21}$ also be considered a behavioral ability classified under all volition, affectivity, and behavior. Higher resilience might also encourage a person with stronger community belonging to get out of the house and attend social events, while lower resilience might serve as a further deterrent to an already weaker level of community belonging (see fig 2). As a result, weaker community belonging may further restrict social participation but only among those with lower resilience and not among those who perceive themselves as having greater strength to drive themselves to grow through adversity and disruptions.

To tailor health-promoting and preventive rehabilitation interventions, it is important to have a better understanding of the processes by which resilience and community belonging are related to social participation. ${ }^{30}$ This study thus aimed to examine (1) the associations between resilience and social participation above and beyond community belonging; and (2) the moderating effect of resilience on the association between community belonging and social participation among community-dwelling 

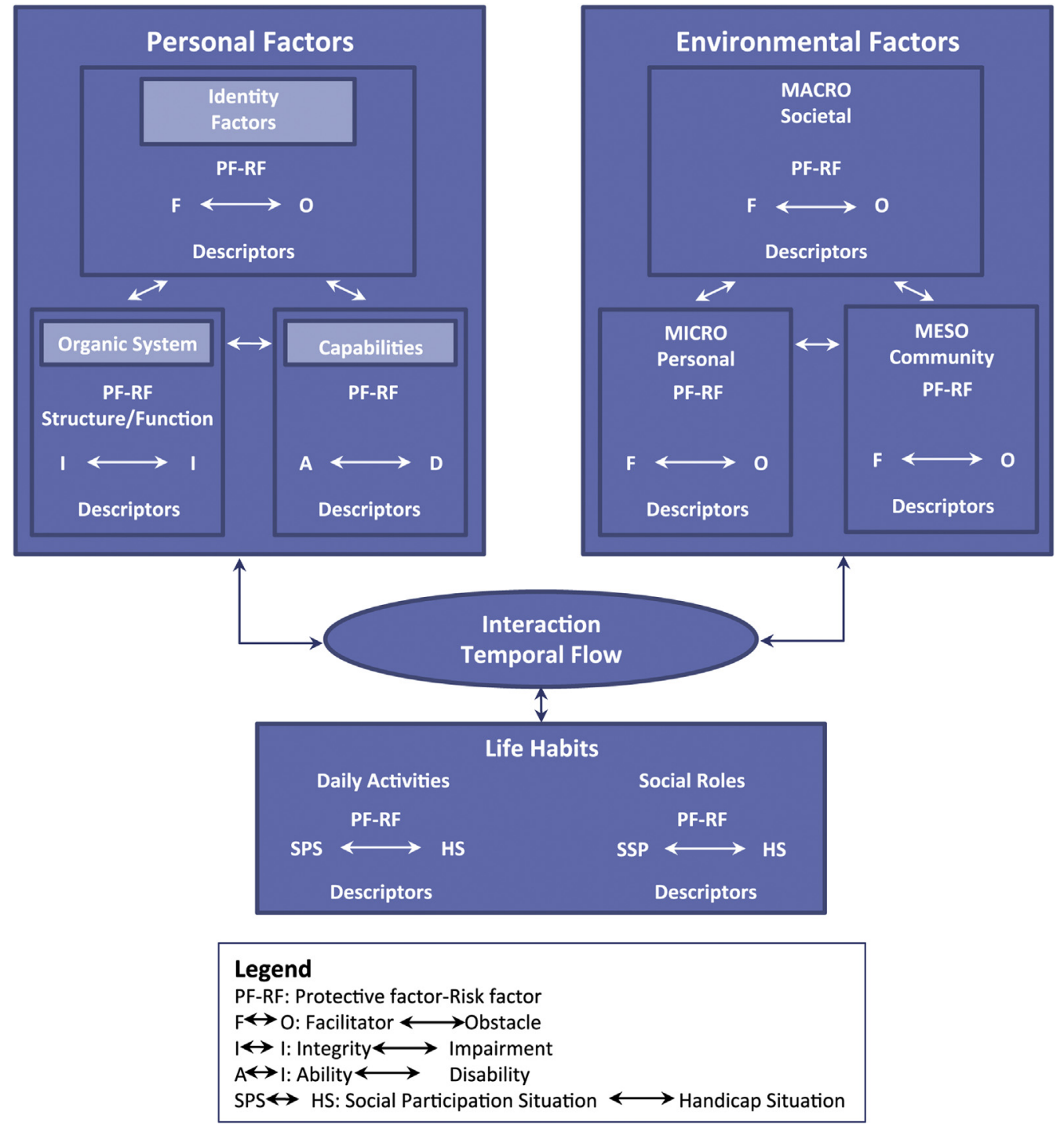

Fig 1 Human Development Model-Disability Creation Process. ${ }^{4}$

older adults (see fig 2). Since social participation differs between women and men, ${ }^{37-39}$ and moderating influences might also be sex-specific, ${ }^{40}$ analyses were performed separately for women and men. The 2 research hypotheses were that (1) higher resilience and stronger community belonging would be associated with greater social participation (main effect; see fig 2); and (2) the positive association between community belonging and social participation would be weakened among both older women and men with lower resilience and strengthened among those with greater resilience (moderating effect; see fig 2).

\section{Methods}

\section{Participants and data collection}

A cross-sectional study was conducted within the Eastern Townships Population Survey research initiative conducted in the summers of 2014 and 2015. Including a mix of urban, semiurban, and rural areas, the Eastern Townships are located in southeastern Quebec (Canada) near the United States border; the population of about 500,000 is mostly French speaking. The present investigation involved community-dwelling adults aged $\geq 60$ years ( 2485 women, 2056 men) who lived in 1 of the 9 geographic units of this region and mostly had complete data on social participation, resilience, and community belonging. Based on a random digit dialing procedure including cellular phones, respondents were randomly selected according to age and sex and to reach an equal number of about 800 participants aged $\geq 18$ years and living in a residential unit or private home in each administrative area of the Eastern Townships. This sample size aimed to reflect the prevalence of public health problems. People living in second homes or cottages, businesses, residential and long-term care centers, rooms in residences for older adults, as well as roomers who did not have a private line, were excluded from the survey. Moreover, based on the interviewers' judgment, respondents with cognitive or other health problems (eg, diseases of the nervous or circulatory system with an impact on communication) that could impede their participation were excluded. Respondents participated in a phone interview lasting 


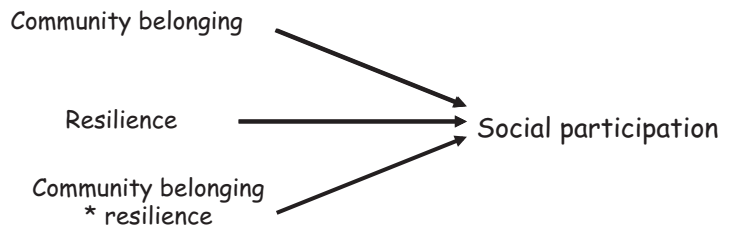

Fig 2 Moderating effect of resilience on the association between community belonging and social participation.

about 35 minutes. The Board of Professional Interviewers, a private firm specializing in conducting surveys, collected selfreported data using qualified interviewers specially trained and supervised for administering the questionnaires, including standardization procedures. The Ethics Committee of the Eastern Townships Integrated University Centre for Health \& Social Services approved the research project (no. 2015-460).

\section{Variables and measurement tools}

\section{Social participation}

Questions taken from Statistics Canada's Participation and Activity Limitation Survey ${ }^{41}$ were used to assess social participation (see fig 2). This 8-item scale addresses the frequency of involvement in 8 social activities: (1) family/friends outside the home; (2) church or religious; (3) sports or physical; (4) educational or cultural; (5) club or fraternal organization; (6) neighborhood, community or professional association; (7) volunteer or charity work; and (8) other recreational. Response options were converted into days per month. ${ }^{33}$ The total score (ie, number of social activities per month) was calculated by summing each item; higher scores indicate greater social participation. The internal consistency of the scale was adequate (Cronbach $\alpha=.72$ ). ${ }^{6}$

\section{Resilience}

Resilience was estimated with the 10-item Connor-Davidson Resilience Scale that captures the ability to cope with adversity. ${ }^{42}$ This short version of the scale assesses the extent to which, over the past month, the respondent felt able to deal with whatever came up. The total score is the sum of the items and ranges from 0 to 40 , with higher scores reflecting greater resilience. The 10item Connor-Davidson Resilience Scale has good construct validity and internal consistency, ${ }^{42}$ including in the current study (Cronbach $\alpha=.88$ ). The normal total mean score $\pm \mathrm{SD}$ of a community sample of older Americans (mean age $\pm \mathrm{SD}$, $77.3 \pm 12.2 \mathrm{y})$ was $31.1 \pm 6.3$. $^{43}$

\section{Community belonging}

Taken from Statistics Canada's General Social Survey-Social Identity, ${ }^{44}$ the sense of belonging to one's local community (see fig 2) was answered on a 5-point Likert scale ranging from 0 ("very weak") to 4 ("very strong"). The question presents good face and content validity.

\section{Sociodemographic and clinical characteristics}

Sociodemographic characteristics were assessed using a series of self-reported questions. History of past and current physical or mental chronic diseases was also considered (eg, diabetes, heart disease, anxiety disorders). Depressive symptoms were considered if the person felt sad, blue, or depressed for $\geq 2$ weeks in a row, or lost interest in most things for $\geq 2$ weeks in the past 12 months.

\section{Analyses}

Descriptive statistics were used to describe the participants using means with SEs or frequency with percentages, according to the type of variables (continuous or categorical, respectively). Women and men were compared using chi-square and $t$ tests to identify differences. As a standard procedure in testing the interaction effect, ${ }^{19}$ resilience and community belonging were centered around their means. To verify the potential moderating effect (see fig 2), multiple regression analyses were performed in 4 steps separately for women and men: (1) testing the main effect of community belonging; (2) testing the main effect of resilience (objective/hypothesis 1); (3) testing the moderating effect by adding the interaction term (community belonging $\times$ resilience; objective/ hypothesis 2); and (4) in line with previous studies, ${ }^{40,45}$ controlling for age, education, and depressive symptoms. To improve interpretation, ${ }^{46}$ results are presented with adjustments for potential confounding variables. Statistical adjustments were also performed considering first potential confounding variables, and results were consistent with the current conclusions (appendixes 1 and 2). In addition to regression coefficients, $P$ values and $R^{2}$ estimates were reported to allow for assessment of the magnitude of associations with each independent variable. To allow for interpretation of interactions, graphic illustration of results was provided. Illustrations were constructed using regression formulas and representative values of both main effects. Assumption of normality was visually verified with histograms. No collinearity problem between the variables was observed using variance inflation factors, and a residual analysis was performed to verify the adequacy of the regression assumptions. $P$ values $<.05$ were considered significant. A sample size of 2485 women or 2056 men allowed detection of correlations superior or equal to .05 based on an alpha significance level of $5 \%$ and a power of $80 \%{ }^{47}$ Analyses were all carried out using proc surveyreg and surveyfreq, SAS version $9.4,{ }^{\mathrm{a}}$ which account for the stratified random sampling strategy weighted to represent the population according to age, sex, and area. Since only a very small proportion of participants had incomplete data (see below), original weights were applied and imputation was not required.

\section{Results}

\section{Participant characteristics}

Among the 2560 older women and 2100 older men who agreed to participate, 2485 women (97.1\%) and 2056 men (97.9\%) had complete data on social participation, resilience, and community belonging. With the exception of being younger $(P<.001$ for both) and fewer being retired $(P<.001$ for women; $P=.02$ for men), the respondents with incomplete data did not differ from other participants aged $\geq 60$ years in terms of chronic diseases, problems in the neighborhood, education, immigrant, living arrangement, housing situation, chronic health problems, depressive symptoms, life satisfaction in neighborhood, neighborhood security, and neighborhood quality of life in the last 2 years. Income $(P=.04)$ and selfrated health $(P=.02)$ of men with incomplete data also differed; that is, more of them had incomes lower than $\$ 20,000$, between $\$ 50,000$ and $\$ 69,999$, or above $\$ 80,000$, and very good or poor selfrated health. Participants were aged between 60 and 106 years, with women having an older mean age than men (table 1). Most of the participants had $<14$ years of schooling, owned their dwelling, were retired, had 1 or 2 chronic conditions, and did not have 
Table 1 Participant characteristics

\begin{tabular}{|c|c|c|c|}
\hline Characteristics & Women $(n=2485)$ & Men $(n=2056)$ & Difference $(P)$ \\
\hline \multicolumn{4}{|l|}{ Continuous variables } \\
\hline Age $(y)$ & $70.4 \pm 0.07$ & $68.9 \pm 0.07$ & $<.001$ \\
\hline Chronic diseases $(/ 9)$ & $1.11 \pm 0.03$ & $1.11 \pm 0.03$ & .98 \\
\hline Problems in neighborhood (/42) & $7.76 \pm 0.13$ & $6.76 \pm 0.14$ & $<.001$ \\
\hline \multicolumn{4}{|l|}{ Categorical variables } \\
\hline Education (y) & & & $<.001$ \\
\hline $2-11$ & $1298(52.2)$ & $866(42.1)$ & \\
\hline $12-13$ & $568(22.9)$ & $462(22.5)$ & \\
\hline$\geq 14$ & $619(24.9)$ & $728(35.4)$ & \\
\hline Immigrant (yes) & $95(3.8)$ & $111(5.4)$ & $<.001$ \\
\hline Income ( $\$$ CAN) & & & $<.001$ \\
\hline$<20,000$ & $517(20.8)$ & $208(10.1)$ & \\
\hline $20,000-29,999$ & 564 (22.7) & $300(14.6)$ & \\
\hline $30,000-49,999$ & $639(25.7)$ & $558(27.1)$ & \\
\hline $50,000-69,999$ & $245(9.9)$ & $358(17.4)$ & \\
\hline $70,000-79,999$ & $90(3.6)$ & $132(6.4)$ & \\
\hline$\geq 80,000$ & $211(8.5)$ & $408(19.8)$ & \\
\hline Missing & 220 (8.9) & $91(4.4)$ & \\
\hline Living arrangement & & & $<.001$ \\
\hline Alone & $1210(48.7)$ & $564(27.4)$ & \\
\hline With other(s) & $1266(50.9)$ & $1492(72.6)$ & \\
\hline Missing & $9(0.4)$ & $0(0)$ & \\
\hline Housing situation & & & $<.001$ \\
\hline Owner & $1725(69.4)$ & $1685(82.0)$ & \\
\hline Tenant & $760(30.6)$ & $371(18.0)$ & \\
\hline Housing location & & & $<.001$ \\
\hline Urban & $912(36.7)$ & $641(31.2)$ & \\
\hline Rural & $1485(59.8)$ & $1357(66.0)$ & \\
\hline Missing & $88(3.5)$ & $58(2.8)$ & \\
\hline Occupation & & & $<.001$ \\
\hline Retired & $2013(81.0)$ & $1508(73.3)$ & \\
\hline Full-time worker & $191(7.7)$ & $356(17.3)$ & \\
\hline Part-time worker & $142(5.7)$ & $131(6.4)$ & \\
\hline Other & $138(5.6)$ & $60(2.9)$ & \\
\hline Missing & $1(0)$ & $1(0)$ & \\
\hline Self-rated health & & & .29 \\
\hline Excellent & $420(16.9)$ & $358(17.4)$ & \\
\hline Very good & $750(30.2)$ & $654(31.8)$ & \\
\hline Good & $769(30.9)$ & $651(31.7)$ & \\
\hline Fair & $440(17.7)$ & $309(15.0)$ & \\
\hline Poor & $107(4.3)$ & $85(4.1)$ & \\
\hline Chronic health problem (yes) & $1576(63.4)$ & $1347(65.5)$ & .17 \\
\hline Depressive symptoms (yes) & $649(26.1)$ & $394(19.2)$ & $<.001$ \\
\hline Life satisfaction in neighborhood & & & .01 \\
\hline Very satisfied & 1559 (62.7) & $1317(64.1)$ & \\
\hline Somewhat satisfied & $793(31.9)$ & $667(32.4)$ & \\
\hline Not very satisfied & $95(3.8)$ & $62(3.0)$ & \\
\hline Not at all satisfied & $27(1.1)$ & $6(0.3)$ & \\
\hline Missing & $10(0.4)$ & $4(0.2)$ & \\
\hline Neighborhood security & & & .04 \\
\hline Completely secure & $1647(66.3)$ & $1450(70.5)$ & \\
\hline Somewhat secure & $772(31.1)$ & $561(27.3)$ & \\
\hline Not very secure & $55(2.2)$ & $33(1.6)$ & \\
\hline Not at all secure & $8(0.3)$ & $9(0.4)$ & \\
\hline Missing & $6(0.2)$ & $5(0.2)$ & \\
\hline Neighborhood quality of life in the last 2 years & & & .03 \\
\hline Increased & $429(17.3)$ & $397(19.3)$ & \\
\hline
\end{tabular}


Table 1 (continued)

\begin{tabular}{|c|c|c|c|}
\hline Characteristics & Women $(n=2485)$ & Men $(n=2056)$ & Difference $(P)$ \\
\hline Decreased & $152(6.1)$ & $101(4.9)$ & \\
\hline Stayed the same & $1829(73.6)$ & $1521(74.0)$ & \\
\hline Does not apply & $60(2.4)$ & $29(1.4)$ & \\
\hline Missing & $15(0.6)$ & $8(0.4)$ & \\
\hline
\end{tabular}

NOTE. Values are mean \pm SE for continuous variables, $n(\%)$ for categorical variables, or as otherwise indicated.

depressive symptoms. Compared with the men, the women were more likely to have less education, live alone, and report depressive symptoms.

\section{Social participation, resilience, and community belonging}

Women had a higher mean for social participation than men (table 2): about 1 more community activity per month with a large range (minimum $=0 / 3$ and maximum $=96 / 118$ respectively for women/men). Specifically, women participated in more religious activities $(P<.001)$, neighborhood, community or professional association activities $(P=.04)$, and volunteer or charity work $(P<.01)$ than men (data not shown). The participants' mean resilience scores were similar to norms and indicated a good ability to cope with adversity, with men scoring higher than women (range, 0-40). Finally, most participants had a strong sense of community belonging, which did not differ according to sex.

\section{Main effects of resilience and community belonging}

For both women and men, stronger community belonging was associated with greater social participation (tables 3 and 4). Specifically, for each 1-unit increase in community belonging, with other covariates held fixed, the social participation of women and men was, on average at the mean resilience score, greater by 3.2 and 2.3 activities per month, respectively. Higher resilience of both women and men was also associated with greater social participation (see tables 3 and 4). Accordingly, for each 5-unit increase in resilience, with other variables held fixed, the social participation of women and men was, on average at the mean resilience score, greater by 0.7 activities per month.

\section{Moderating effect of resilience}

After controlling for age, education, and depressive symptoms, an additional significant moderating effect of resilience on the

Table 2 Raw scores for main variables

\begin{tabular}{llll}
\hline $\begin{array}{l}\text { Main Continuous } \\
\text { Variables }\end{array}$ & $\begin{array}{l}\text { Women } \\
(\mathrm{n}=2485)\end{array}$ & $\begin{array}{l}\text { Men } \\
(\mathrm{n}=2056)\end{array}$ & $\begin{array}{l}\text { Difference } \\
(P)\end{array}$ \\
\hline $\begin{array}{l}\text { Social participation } \\
\quad \text { (no. of activities/mo) }\end{array}$ & $18.7 \pm 0.32$ & $17.5 \pm 0.35$ & $<.01$ \\
$\begin{array}{l}\text { Resilience } \\
\quad(\text { CD-RISC-SF;/40) }\end{array}$ & $31.0 \pm 0.15$ & $32.0 \pm 0.17$ & $<.001$ \\
$\begin{array}{l}\text { Community belonging } \\
(/ 4)\end{array}$ & $2.3 \pm 0.03$ & $2.4 \pm 1.4$ & .01 \\
\hline
\end{tabular}

NOTE. Values are mean \pm SE or as otherwise indicated.

Abbreviation: CD-RISC-SF, Connor-Davidson Resilience Scale-Short Form. association between community belonging and social participation was observed for women $(\beta=.08 \pm .04 ; P=.03)$ (see table 3 ) and, especially, men $(\beta=.10 \pm .06 ; P<.01)$ (see table 4$)$. In other words, when resilience was higher, greater community belonging further enhanced social participation (figs 3 and 4). However, when older adults had lower resilience, no association was observed between community belonging and social participation. In other words, resilience was associated with greater social participation among women and men with stronger community belonging, but was lower among those, especially men, with weaker community belonging, who appeared to disengage from social participation (see figs 3 and 4).

\section{Discussion}

This study shows that higher resilience was associated with greater social participation among women and men with stronger community belonging. Resilience was, however, less associated with social participation among women and, especially, men with a weaker sense of community belonging.

\section{Community belonging and resilience as correlates of social participation}

These results are consistent with previous studies supporting the importance of community belonging for social participation. For example, Richard et $\mathrm{al}^{33}$ showed higher social participation in older adults with a stronger sense of belonging to the neighborhood. Two qualitative studies also found links between resilience, community belonging, and social participation. First, older adults from an urban community in California reported that they could maintain their social participation through factors linked to community belonging such as connecting with diverse people, accessing community resources, participating in health and action social groups, and maintaining relationships with friends and family. Others factors were also linked to resilience, namely finding activities that express deeply held values, being willing to try new things, retaining a positive attitude, and finding ways to be recognized for contributions to society. ${ }^{34}$ Second, older adults from an urban community in the Eastern Townships with various levels of disability reported that inner life, a concept linked to resilience including philosophy of life and personal growth, influenced their quality of life. ${ }^{10}$ Moreover, factors linked to community belonging such as feeling appreciated and adaptation of the physical and social environment to the person's needs and preferences also influenced their quality of life.

In the current study, social activities most frequently reported were visiting family members/friends as well as educational or cultural activities for women, and sports or physical activities for men (data not shown). Social participation increases or maintains older adults' physical capacities and health, which might in turn increase the likelihood of resilience and community belonging. 
Table 3 Regression coefficients in the multivariate model estimating main and moderating effects of resilience on the association between community belonging and social participation in women $(n=2485)$

\begin{tabular}{|c|c|c|c|c|c|c|c|c|}
\hline \multirow[b]{2}{*}{ Variable } & \multicolumn{2}{|c|}{ Model 1} & \multicolumn{2}{|c|}{ Model 2} & \multicolumn{2}{|c|}{ Model 3} & \multicolumn{2}{|l|}{ Model 4} \\
\hline & $\beta(S E)$ & $P$ & $\beta(S E)$ & $P$ & $\beta(\mathrm{SE})$ & $P$ & $\beta(\mathrm{SE})$ & $P$ \\
\hline Community belonging $(/ 4)$ & $3.35(0.31)$ & $<0.001$ & $3.23(0.24)$ & $<.001$ & $3.24(0.24)$ & $<.001$ & $3.18(0.23)$ & $<.001$ \\
\hline Resilience (CD-RISC-SF) & & & $0.20(0.05)$ & $<.001$ & $0.22(0.05)$ & $<.001$ & $0.14(0.05)$ & $<.01$ \\
\hline Interaction term (community belonging * resilience) & & & & & $0.09(0.04)$ & .02 & $0.08(0.04)$ & .03 \\
\hline Age & & & & & & & $0.01(0.04)$ & .80 \\
\hline Education $(y)$ & & & & & & & & $<.001$ \\
\hline $2-11$ & & & & & & & 0 & \\
\hline $12-13$ & & & & & & & $2.11(0.71)$ & $<.01$ \\
\hline$\geq 14$ & & & & & & & $5.98(0.78)$ & $<.001$ \\
\hline \multirow[t]{2}{*}{ Depressive symptoms } & \multirow{2}{*}{\multicolumn{2}{|c|}{$R^{2}=.086$}} & \multirow{2}{*}{\multicolumn{2}{|c|}{$R^{2}=.095$}} & \multirow{2}{*}{\multicolumn{2}{|c|}{$R^{2}=.097$}} & $-0.58(0.67)$ & .39 \\
\hline & & & & & & & $R^{2}=.126$ & \\
\hline
\end{tabular}

NOTE. Model 1: Bivariate model testing the main effect of community belonging on social participation. Model 2: Multivariate model considering community belonging and resilience. Model 3: Multivariate model estimating the moderating effect of resilience on the association between social participation and community belonging. Model 4: Previous model (3) but adjusted for age, education, and depressive symptoms.

Abbreviation: CD-RISC-SF, Connor-Davidson Resilience Scale-Short Form.

However, community belonging and resilience explained only small percentages of the variance in social participation for women, and even smaller percentages for men. Reasons for the limited variance explained might include (1) small variation in the community belonging scores, and (2) lack of consideration of a broad array of personal and environmental variables that extend beyond resilience and community belonging. In fact, the proportion of people reporting very strong belonging to the local community was much higher in 2013 in both Canada $(29 \%-47 \%)$ and Quebec (32\%), ${ }^{44}$ compared with the current sample $(13.8 \%$ for women; $15.3 \%$ for men). Nevertheless, the mean social participation of participants in this study was much higher (18.7 activities for women; 17.5 for men) than in 2008 through 2009 in Canada (15.2 for women; 14.5 for men) and Quebec (14.2 for women; 12.8 for men). ${ }^{6}$

Although associations between these concepts have been identified, some issues remain. There are important differences in the operationalization of social participation ${ }^{48}$ and resilience in the literature: some tools emphasize home participation ${ }^{49}$ or the resilience process, ${ }^{50}$ while others, as in the present investigation, focus exclusively on community participation ${ }^{41}$ and the ability to cope with adversity. ${ }^{42}$ In addition, the impact of study sample and design on results was previously highlighted $^{51}$ and requires further investigation. For example, fewer associations between resilience, community belonging, and participation may be found when individuals are studied at a specific time in their lives, since people may adapt to, or modify, their environment, ${ }^{49}$ personal characteristics such as resilience, ${ }^{12}$ as well as their social participation. ${ }^{4}$

\section{Resilience as a moderator}

To our knowledge, this is the first study to present evidence of a moderating effect of resilience on the association between community belonging and social participation. Older adults with higher resilience might present different levels of engagement in social activities or belonging to the community. One longitudinal study $^{52}$ showed that the frequency of women's involvement in leisure activities was less likely than that of men to be affected by decreased health. Such differences might be explained by prior

Table 4 Regression coefficients in the multivariate model estimating main and moderating effects of resilience on the association between community belonging and social participation in men $(n=2056)$

\begin{tabular}{|c|c|c|c|c|c|c|c|c|}
\hline \multirow[b]{2}{*}{ Variable } & \multicolumn{2}{|c|}{ Model 1} & \multicolumn{2}{|c|}{ Model 2} & \multicolumn{2}{|c|}{ Model 3} & \multicolumn{2}{|l|}{ Model 4} \\
\hline & $\beta(\mathrm{SE})$ & $P$ & $\beta(\mathrm{SE})$ & $P$ & $\beta(\mathrm{SE})$ & $P$ & $\beta(\mathrm{SE})$ & $P$ \\
\hline Community belonging & $2.58(0.26)$ & $<.001$ & $2.43(0.26)$ & $<.001$ & $2.36(0.26)$ & $<.001$ & $2.28(0.26)$ & $<.001$ \\
\hline Resilience (CD-RISC-SF) & & & $0.18(0.05)$ & $<.001$ & $0.18(0.05)$ & .001 & $0.14(0.05)$ & $<.01$ \\
\hline Interaction term (community belonging * resilience) & & & & & $0.11(0.04)$ & $<.01$ & $0.10(0.04)$ & $<.01$ \\
\hline Age & & & & & & & $0.10(0.06)$ & .06 \\
\hline Education (y) & & & & & & & & $<.001$ \\
\hline $2-11$ & & & & & & & 0 & \\
\hline $12-13$ & & & & & & & $1.61(0.84)$ & .06 \\
\hline$\geq 14$ & & & & & & & $4.61(0.78)$ & $<.001$ \\
\hline \multirow[t]{2}{*}{ Depressive symptoms } & \multirow{2}{*}{\multicolumn{2}{|c|}{$R^{2}=.052$}} & \multirow{2}{*}{\multicolumn{2}{|c|}{$R^{2}=.058$}} & \multirow{2}{*}{\multicolumn{2}{|c|}{$R^{2}=.063$}} & $-1.21(0.75)$ & .10 \\
\hline & & & & & & & $R^{2}=.087$ & \\
\hline
\end{tabular}

NOTE. Model 1: Bivariate model testing the main effect of community belonging on social participation. Model 2: Multivariate model considering community belonging and resilience. Model 3: Multivariate model estimating the moderating effect of resilience on the association between social participation and community belonging. Model 4: Previous model (3) but adjusted for age, education, and depressive symptoms. Abbreviation: CD-RISC-SF, Connor-Davidson Resilience Scale-Short Form. 


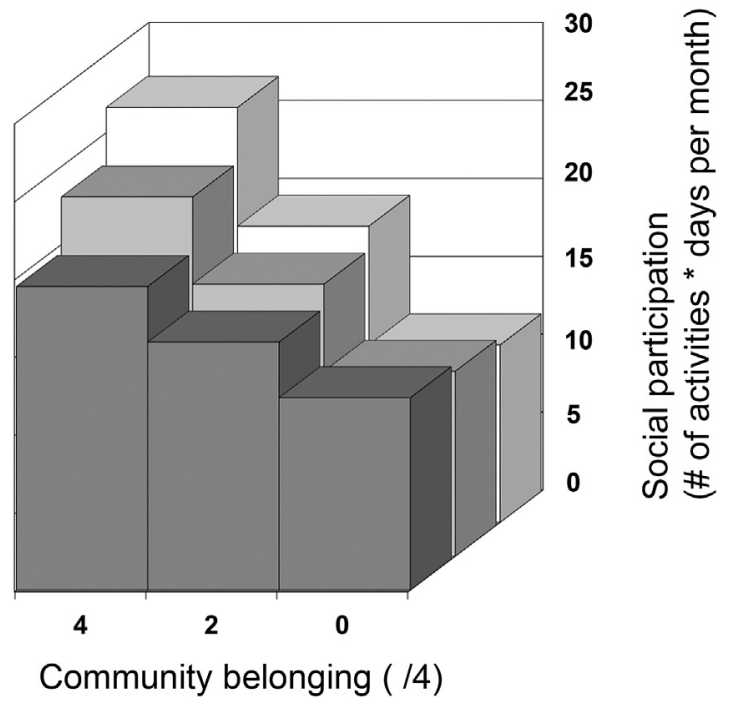

Fig 3 Decomposition of the moderating effect of resilience on the association between community belonging and social participation among women $(n=2485)$. White bars, estimates for participants with high levels of resilience (39/40); gray bars, estimates for participants with moderate resilience $(26 / 40)$; black bars, estimates for participants with weak resilience (13/40), according to the Connor-Davidson Resilience Scale-Short Form.

social participation habits, ${ }^{53}$ meaning of social activities, ${ }^{54}$ different obligations, and relevance of the community. In the present study, many of the older women lived alone and might have more social obligations (eg, caring for and nurturing others $)^{55}$ associated with their participation.

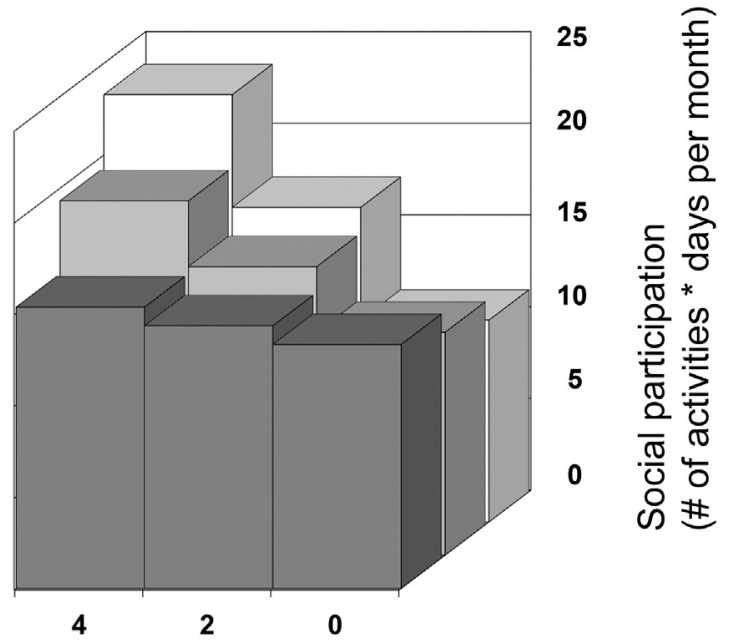

\section{Community belonging ( /4)}

Fig 4 Decomposition of the moderating effect of resilience on the association between community belonging and social participation among men $(n=2056)$. White bars, estimates for participants with high levels of resilience (39/40); gray bars, estimates for participants with moderate resilience $(26 / 40)$; black bars, estimates for participants with weak resilience (13/40), according to the Connor-Davidson Resilience Scale-Short Form.

\section{Implications for practice and research}

First, the results of this study suggest ways to tailor healthpromoting and preventive rehabilitation interventions. Since higher resilience might encourage older adults with greater community belonging to get out of the house and attend social events, these interventions should consider resilience, that might be developed. ${ }^{12,56,57}$ Lower resilience might also serve as a further deterrent to an already weaker level of community belonging and, as a result, weaker community belonging may further restrict social participation. Other studies are needed to confirm these findings and develop interventions. Second, public policy decisions affect land use and community design, ${ }^{58}$ which can foster community belonging, social participation, ${ }^{59}$ and health. ${ }^{60}$ If we are to foster social participation among older adults, current trends that provide social opportunities far from people's community require rethinking. Moreover, important questions have been raised, including whether or not increasing resilience helps to improve social participation of older adults. Such questions definitely require further research. Finally, the following studies are warranted: (1) replication of the main and moderating effects; (2) exploration of other personal and environmental factors that might enhance social participation; and (3) comparisons of older adults with different disabilities or social support levels or who live in different types of housing or rural locations. Longitudinal and experimental designs would also be of interest.

\section{Study limitations}

Measures used in this study were all self-reported and involved an operationalization of social participation, resilience, and community belonging. Also, because of the cross-sectional design, we could not evaluate whether and how community design interventions that improve resilience and community belonging might increase the social participation of older women and men. Finally, this study was carried out with a sample that may not be fully representative of older adults living in the community because the participants had a limited number of chronic diseases and lived in urban or rural areas but not in metropolises or in a collective household.

\section{Conclusions}

This study shows that higher resilience and stronger community belonging were associated with greater social participation among older adults. Moreover, resilience moderates the association between community belonging and social participation among community-dwelling older women and, especially, men. Interventions enhancing individual and community resilience might be needed to encourage social participation at older ages. In addition, interventions targeting social participation should consider the potential effects of resilience on improving community belonging. Future studies should replicate these findings and investigate why resilience moderates the associations between community belonging and social participation among older women and men.

\section{Supplier}

a. SAS version 9.4; SAS Institute Inc. 


\section{Keywords}

Adaptation, psychological; Community integration; Community participation; Quebec; Rehabilitation; Residence characteristics

\section{Corresponding author}

Mélanie Levasseur, OT(C), PhD, Research Centre on Aging, University Centre for Health \& Social Services-Sherbrooke
Hospital University Centre, 1036 Belvédère South, Rm 4436, Sherbrooke, Québec, Canada J1H 4C4. E-mail address: Melanie. Levasseur@USherbrooke.ca.

\section{Acknowledgments}

We thank Modou Sene and Lise Trottier for their help with the statistical analyses, and the older adults who participated in the Eastern Townships Population Survey.

Appendix 1 Regression coefficients in the multivariate model estimating main and moderating effects of resilience on the association between community belonging and social participation in women $(n=2485)$, adjusted for age, education, and depressive symptoms

\begin{tabular}{|c|c|c|c|c|c|c|}
\hline \multirow[b]{2}{*}{ Variable } & \multicolumn{2}{|c|}{ Model 1} & \multicolumn{2}{|c|}{ Model 2} & \multicolumn{2}{|c|}{ Model 3} \\
\hline & $\beta(\mathrm{SE})$ & $P$ & $\beta(\mathrm{SE})$ & $P$ & $\beta(\mathrm{SE})$ & $P$ \\
\hline Constant & $16.4(3.01)$ & $<.001$ & $16.2(3.01)$ & $<.001$ & $16.20(3.0)$ & $<.001$ \\
\hline Age & $0.01(0.04)$ & .83 & $0.01(0.04)$ & .78 & $0.01(0.04)$ & .80 \\
\hline Education (y) & & $<.001$ & & $<.001$ & & $<.001$ \\
\hline $2-11$ & 0 & & 0 & & 0 & \\
\hline $12-13$ & $2.25(0.72)$ & $<.001$ & $2.11(0.72)$ & $<.01$ & $2.11(0.71)$ & $<.01$ \\
\hline$\geq 14$ & $6.32(0.79)$ & $<.001$ & $6.03(0.78)$ & $<.001$ & $5.98(0.78)$ & $<.001$ \\
\hline Depressive symptoms & $-0.90(0.67)$ & .18 & $-0.58(0.67)$ & .39 & $-0.58(0.67)$ & .39 \\
\hline Community belonging & $3.24(0.23)$ & $<.001$ & $3.18(0.23)$ & $<.001$ & $3.18(0.23)$ & $<.001$ \\
\hline Resilience (CD-RISC-SF) & & & $0.13(0.05)$ & $<.01$ & $0.14(0.05)$ & $<.01$ \\
\hline \multirow[t]{2}{*}{ Interaction term (resilience ${ }^{*}$ community belonging) } & \multirow{2}{*}{\multicolumn{2}{|c|}{$R^{2}=.121$}} & \multirow{2}{*}{\multicolumn{2}{|c|}{$R^{2}=.124$}} & $0.08(0.04)$ & .03 \\
\hline & & & & & $R^{2}=$ & \\
\hline
\end{tabular}

NOTE. Model 1: Multivariate model testing the main effect of community belonging on social participation adjusted for age, education, and depressive symptoms. Model 2: Multivariate model considering community belonging and resilience adjusted for age, education, and depressive symptoms. Model 3: Multivariate model estimating the moderating effect of resilience on the association between social participation and community belonging adjusted for age, education, and depressive symptoms.

Abbreviation: CD-RISC-SF, Connor-Davidson Resilience Scale-Short Form.

Appendix 2 Regression coefficients in the multivariate model estimating main and moderating effects of resilience on the association between community belonging and social participation in men $(n=2056)$, adjusted for age, education, and depressive symptoms

\begin{tabular}{|c|c|c|c|c|c|c|}
\hline \multirow[b]{2}{*}{ Variable } & \multicolumn{2}{|c|}{ Model 1} & \multicolumn{2}{|c|}{ Model 2} & \multicolumn{2}{|c|}{ Model 3} \\
\hline & $\beta(S E)$ & $P$ & $\beta(\mathrm{SE})$ & $P$ & $\beta(\mathrm{SE})$ & $P$ \\
\hline Constant & $9.15(3.72)$ & .01 & $8.26(3.74)$ & .03 & $8.22(3.74)$ & .03 \\
\hline Age & $0.09(0.05)$ & .09 & $0.10(0.06)$ & .06 & $0.10(0.06)$ & .06 \\
\hline Education (y) & & $<.001$ & & $<.001$ & & $<.001$ \\
\hline $2-11$ & 0 & & 0 & & 0 & \\
\hline $12-13$ & $1.87(0.84)$ & .03 & $1.63(0.84)$ & .052 & $1.61(0.84)$ & .055 \\
\hline$\geq 14$ & $4.92(0.78)$ & $<.001$ & $4.65(0.78)$ & $<.001$ & $4.61(0.78)$ & $<.001$ \\
\hline Depressive symptoms & $-1.60(0.74)$ & .03 & $-1.27(0.75)$ & .09 & $-1.21(0.75)$ & .10 \\
\hline Community belonging & $2.45(0.26)$ & $<.001$ & $2.35(0.26)$ & $<.001$ & $2.28(0.26)$ & $<.001$ \\
\hline Resilience (CD-RISC-SF) & & & $0.13(0.05)$ & .01 & $0.14(0.05)$ & $<.01$ \\
\hline \multirow[t]{2}{*}{ Interaction term (resilience ${ }^{*}$ community belonging) } & \multirow{2}{*}{\multicolumn{2}{|c|}{$R^{2}=.081$}} & \multirow{2}{*}{\multicolumn{2}{|c|}{$R^{2}=.084$}} & $0.10(0.04)$ & $<.01$ \\
\hline & & & & & \multicolumn{2}{|c|}{$R^{2}=.087$} \\
\hline
\end{tabular}

NOTE. Model 1: Multivariate model testing the main effect of community belonging on social participation adjusted for age, education, and depressive symptoms. Model 2: Multivariate model considering community belonging and resilience adjusted for age, education, and depressive symptoms. Model 3: Multivariate model estimating the moderating effect of resilience on the association between social participation and community belonging, adjusted for age, education, and depressive symptoms.

Abbreviation: CD-RISC-SF, Connor-Davidson Resilience Scale-Short Form. 


\section{References}

1. World Health Organization. Active ageing: a policy framework. Madrid: Spain; 2002.

2. Levasseur M, Richard L, Gauvin L, Raymond E. Inventory and analysis of definitions of social participation found in the aging literature: proposed taxonomy of social activities. Soc Sci Med 2010; 71:2141-9.

3. Holt-Lunstad J, Smith TB, Layton JB. Social relationships and mortality risk: a meta-analytic review. PLoS Med 2010;7:e1000316.

4. Fougeyrollas P. Le funambule, le fil et la toile: transformations réciproques du sens du handicap. [The tightrope walker, wire and canvas. Reciprocal transformations of the meaning of disability] [French]. Québec City, Canada: Presses de 1'Université Laval; 2010.

5. Warburton J, McLaughlin D. Doing it from your heart: the role of older women as informal volunteers. J Women Aging 2006; 18:55-72.

6. Naud D, Levasseur M. Social participation and environmental barriers among aging Canadians: distribution and differences in gender, age and location. In: Rowe KT, editor. Social isolation, participation and impact on mental health. Hauppauge: Nova Science; 2015. p 1-25.

7. Young F, Glasgow N. Voluntary social participation and health. Res Aging 1998;20:339-62.

8. Mendes de Leon CF, Seeman TE, Baker DI, Richardson ED, Tinetti ME. Self-efficacy, physical decline and change in functioning in community-living elders: a prospective study. J Gerontol B Psychol Sci Soc Sci 1996;51:S183-90.

9. Hebert R, Brayne C, Spiegelhalter D. Incidence of functional decline and improvement in a community-dwelling, very elderly population. Am J Epidemiol 1997;145:935-44.

10. Levasseur M, St-Cyr Tribble D, Desrosiers J. Meaning of quality of life for older adults: importance of human functioning components. Arch Gerontol Geriatr 2009;49:e91-100.

11. Maslow A. A symbol for holistic thinking. Persona 1947;1:24-5.

12. American Psychological Association. The road to resilience. Washington (DC): American Psychological Association; 2009.

13. Windsor TD, Hunter ML, Browne-Yung K. Ageing well: building resilience in individuals and communities. Flinders Centre for Ageing Studies, Office for the Ageing. South Australia; 2015. Available at: http://www.sahealth.sa.gov.au/wps/wcm/connect/ e35948004ac667418a67de0b65544981/Ageing +Well+Building +Re silience + in + Individuals + and + Communities. pdf?MOD $=$ AJPERES $\&$ CACHEID $=$ e35948004ac667418a67de0b65544981. Accessed May 16, 2017.

14. Mittelmark MB, Sagy S, Eriksson M, et al. The handbook of salutogenesis. Switzerland: Springer International; 2017. p 461.

15. Richardson GE. The metatheory of resilience and resiliency. J Clin Psychol 2002;58:307-21.

16. Herrman HM, Stewart DE, Diaz-Granados NM, Berger EL, Jackson BP, Yuen TB. What is resilience? Can J Psychiatry 2011;56:258-65.

17. Anaut M. La résilience: surmonter les traumatismes [Resilience: overcoming trauma]. 2nd ed. Paris: Armand Colin; 2008.

18. Wingoa A, Wrennb G, Pelletiera T, Gutmana A, Bradleya B, Resslera K. Moderating effects of resilience on depression in individuals with a history of childhood abuse or trauma exposure. J Affect Disord 2010;126:411-4.

19. Baron RM, Kenny DA. The moderator-mediator variable distinction in social psychological research: conceptual, strategic, and statistical considerations. J Pers Soc Psychol 1986;51:1173-82.

20. Li-ju J, Jieh-jiuh W. Disaster resilience in a Hakka community in Taiwan. J Pacific Rim Psychol 2009;3:55-65.

21. Davydov DM, Stewart R, Ritchie K, Chaudieu I. Resilience and mental health. Clin Psychol Rev 2010;30:479-95.

22. Iacoviello BM, Charney DS. Psychosocial facets of resilience: implications for preventing posttrauma psychopathology, treating trauma survivors, and enhancing community resilience. Eur J Psychotraumatol 2014;5:1-10.
23. Southwick SM, Pietrzak RH, Tsai J, Krystal JH, Charney D. Resilience: an update. PTSD Res Q 2014;25:1-4.

24. White B, Driver S, Warren AM. Resilience and indicators of adjustment during rehabilitation from a spinal cord injury. Rehabil Psychol 2010;55:23-32.

25. Richer MC, Ezer H. Understanding beliefs and meanings in the experience of cancer: a concept analysis. J Adv Nurs 2000;32:110815.

26. Canadian Institute for Health Information. Improving the health of Canadians: an introduction to health in urban places. Ottawa: $\mathrm{Ca}-$ nadian Institute for Health Information; 2006.

27. Glass TA, Balfour JL. Neighborhoods, aging, and functional limitations. In: Kawachi I, Berkman LF, editors. Neighborhoods and health. New York: Oxford Univ Pr; 2003. p 303-34.

28. Lawton MP, editor. Environment and aging. 2nd ed. Monterey: Brooks/Cole; 1986.

29. Bowling A, Stafford M. How do objective and subjective assessments of neighbourhood influence social and physical functioning in older age? Findings from a British survey of ageing. Soc Sci Med 2007;64: 2533-49.

30. Burke J, O'Campo P, Salmon C, Walker R. Pathways connecting neighborhood influences and mental well-being: socioeconomic position and gender differences. Soc Sci Med 2009;68:1294-304.

31. Potvin L, Hayes MV. Place and health research in Canada. Can J Public Health 2007;98:S6-7.

32. Shields M. Community belonging and self-perceived health. Statistics Canada 2008; Available at: http://www.statcan.gc.ca/pub/82-003x/2008002/article/10552-eng.pdf. Accessed May 16, 2017.

33. Richard L, Gauvin L, Gosselin C, Laforest S. Staying connected: neighbourhood correlates of social participation among older adults living in an urban environment in Montreal, Quebec. Health Promot Int 2009;24:46-57.

34. Andonian L, MacRae A. Well older adults within an urban context: strategies to create and maintain social participation. Br J Occup Ther 2011;74:2-11.

35. World Health Organization. International Classification of Functioning, Disability and Health. Geneva: World Health Organization; 2001.

36. Levasseur M, Desrosiers J, St-Cyr Tribble D. Conceptual comparison of the Disability Creation Process and International Classification of Functioning, Disability and Health models. Can J Occup Ther 2007; 74(5 Suppl):233-42.

37. Desrosiers J, Robichaud L, Demers L, Gelinas I, Noreau L, Durand D. Comparison and correlates of participation in older adults without disabilities. Arch Gerontol Geriatr 2009;49:397-403.

38. Egan M, Tannahill C, Petticrew M, Thomas S. Psychosocial risk factors in home and community settings and their associations with population health and health inequalities: a systematic meta-review. BMC Public Health 2008;8:239.

39. Levasseur M, Cohen AA, Dubois M-F, et al. Environmental factors associated with social participation of older adults living in metropolitan, urban and rural areas, from the NuAge study. Am J Public Health 2015;105:1718-25.

40. Levasseur M, Gauvin L, Richard L, et al. Associations between perceived proximity to neighborhood resources, disability, and social participation among community-dwelling older adults: results from the VoisiNuAge study. Arch Phys Med Rehabil 2011; 92:1979-86.

41. Statistics Canada. Participation and activity limitation survey. Ontario: Statistics Canada; 2006.

42. Campbell-Sills L, Stein MB. Psychometric analysis and refinement of the Connor-Davidson Resilience Scale (CD-RISC): validation of a 10-item measure of resilience. J Trauma Stress 2007;20:1019-28.

43. Jeste D, Savia G, Thompson W, et al. Association between older age and more successful aging: critical role of resilience and depression. Am J Psychiatry 2013;170:188-96.

44. Statistics Canada. General social survey social identity. Ontario: Statistics Canada; 2013. 
45. Greenfield EA, Marks NF. Continuous participation in voluntary groups as a protective factor for the psychological well-being of adults who develop functional limitations: evidence from the $\mathrm{Na}$ tional Survey of Families and Households. J Gerontol B Psychol Sci Soc Sci 2007;62:S60-8.

46. Streiner DL, Norman GR, Cairney J. Health measurement scales: a practical guide to their development and use. 5th ed. Oxford Univ Pr; Oxford, UK; 2014.

47. Machin D, Campbell M, Tan S, Tan S. Sample size tables for clinical studies. 3rd ed. Chichester: Wiley-Blackwell; 2009.

48. Lariviere N. Analyse du concept de la participation sociale: definitions, cas d'illustration, dimensions de l'activite et indicateurs [Analysis of the concept of social participation: definitions, illustration, dimensions of activity and indicators.]. Can J Occup Ther 2008;75:114-27.

49. Keysor JJ, Jette AM, Coster W, Bettger JP, Haley SM. Association of environmental factors with levels of home and community participation in an adult rehabilitation cohort. Arch Phys Med Rehabil 2006;87:1566-75.

50. Abramson DM, Grattan LM, Mayer B, et al. The resilience activation framework: a conceptual model of how access to social resources promotes adaptation and rapid recovery in post-disaster settings. J Behav Health Serv Res 2014:42:42-57.

51. Hoenig H, Giacobbi P, Levy CE. Methodological challenges confronting researchers of wheeled mobility aids and other assistive technologies. Disabil Rehabil Assist Technol 2007;2:159-68.
52. Stanley D, Freysinger VJ. The impact of age, health, and sex on the frequency of older adults' leisure activity participation: a longitudinal study. Act Adapt Aging 1995;19:31-42.

53. Bukov A, Maas I, Lampert T. Social participation in very old age: cross-sectional and longitudinal findings from BASE. Berlin Aging Study. J Gerontol B Psychol Sci Soc Sci 2002;57:P510-7.

54. Hammel J, Magasi S, Heinemann A, Whiteneck G, Bogner J, Rodriguez E. What does participation mean? An insider perspective from people with disabilities. Disabil Rehabil 2008;30:1445-60.

55. Herzog AR, Markus HR. The self-concept in life span and aging research. In: Bengtson V, Schaie K, editors. Handbook of theories of aging. New York: Springer; 1999. p 227-52.

56. Maggio MJ. Hurricane Katrina: resiliency, the other side of tragedy. Fed Probat 2006;70:42-4.

57. Seery MD. Resilience: a silver lining to experiencing adverse life events? Curr Dir Psychol Sci 2011;20:390-4.

58. Farhang L, Bhatia R, Scully CC, Corburn J, Gaydos M, Malekafzali S. Creating tools for healthy development: case study of San Francisco's Eastern Neighborhoods Community Health Impact Assessment. J Public Health Manag Pract 2008;14:255-65.

59. Glandon RP. Built environment and health: considerations from the field. J Public Health Manag Pract 2008;14:211-3.

60. Moore JB. The built environment and physical activity: influencing physical activity through healthy design. J Public Health Manag Pract 2008;14:209-10. 